\title{
ATRIBUTOS QUÍMICOS DE SOLO CULTIVADO COM DIFERENTES CULTURAS DE COBERTURA ${ }^{1}$
}

\author{
Pedro Marques da Silveira², Paulo César Ribeiro da Cunha ${ }^{3}$, \\ Luís Fernando Stone ${ }^{2}$, Glênio Guimarães dos Santos ${ }^{3}$
}

\begin{abstract}
CHEMICAL ATTRIBUTES OF A SOIL CULTIVATED WITH DIFFERENT COVER CROPS

The effect of cover crops annually implanted in the summer, since 2001, under no-tillage system, on the soil chemical attributes was evaluated. The experiment was carried out in Embrapa Rice \& Beans, in Santo Antônio de Goiás, GO, Brazil, in a Dystrophic Red Latosol (Red Oxisol). Brachiaria brizantha, corn (Zea mays L.) associated with B. brizantha, pigeon pea, millet, Panicum maximum, sorghum, Stylosanthes guianensis, and sunn hemp were used as cover crops. Sixty days after the cut of the cover crops, common bean crop was implanted, under a central pivot sprinkler irrigation system. In November 2001, 2005, and 2006, soil samples were collected in the depths of $0-5 \mathrm{~cm}$, $5-10 \mathrm{~cm}$, and $10-20 \mathrm{~cm}$. Immediately after the 2005 sampling, it was applied 4,000 $\mathrm{kg} \mathrm{ha}^{-1}$ of dolomitic lime, in all the experimental area. Cover crops affected soil $\mathrm{pH}$ and magnesium content in the superficial layer. Soil under millet showed higher phosphorus content in subsuperficial layers, in relation to the initial values. The soil $\mathrm{P}$ and $\mathrm{Cu}$ contents were higher in the subsuperficial layers, while the other chemical attributes were higher in the superficial layer. There was movement of $\mathrm{Ca}$ and $\mathrm{Mg}$ in the soil profile, one year after the application of lime in the soil surface.
\end{abstract}

KEY-WORDS: No-tillage system; grasses; Leguminosae; soil fertility.

\section{INTRODUÇÃO}

Na região do Cerrado, a partir do final da década de 1980, tem havido expressivo interesse, por parte dos agricultores, na adoção de sistemas de manejo do solo que apresentem menor custo e mitiguem o processo erosivo do solo. A adoção de sistemas conservacionistas, como o plantio direto, tem se apresentado como alternativa viável para assegurar a sustentabilidade do uso agrícola do solo, principalmente dos latossolos. O sucesso do sistema

\section{RESUMO}

Avaliaram-se os efeitos de culturas de cobertura implantadas anualmente no verão, desde 2001, em sistema plantio direto, sobre os atributos químicos do solo. O experimento foi conduzido na Embrapa Arroz e Feijão, em Santo Antônio de Goiás, GO, em Latossolo Vermelho distrófico. Utilizaramse as seguintes culturas de cobertura: braquiária, milho consorciado com braquiária, guandu, milheto, capim mombaça, sorgo, estilosantes e crotalária. Sessenta dias após o corte das coberturas, implantou-se a cultura do feijoeiro, sob irrigação por aspersão, em sistema pivô central. Em novembro de 2001, 2005 e 2006, coletaram-se amostras de solo, nas profundidades de $0-5 \mathrm{~cm}, 5-10 \mathrm{~cm}$ e $10-20 \mathrm{~cm}$. Logo após a coleta de 2005 , foram aplicados $4.000 \mathrm{~kg} \mathrm{ha}^{-1}$ de calcário dolomítico, em toda $\mathrm{a}$ área experimental. As culturas de cobertura afetaram o $\mathrm{pH}$ e o teor de magnésio do solo, na camada superficial. O solo sob milheto apresentou maiores teores de fósforo, nas camadas subsuperficiais, em relação aos teores iniciais. Os teores de fósforo e cobre foram maiores nas camadas subsuperficiais do solo, enquanto os demais atributos químicos apresentaram maiores valores na camada superficial. Houve movimentação de Ca e Mg no perfil do solo, um ano após a aplicação do calcário na superfície.

PALAVRAS-CHAVE: Sistema plantio direto; gramíneas; leguminosas; fertilidade do solo.

está no fato de a palhada acumulada pelas culturas de cobertura e restos culturais de lavouras comerciais proporcionarem um ambiente favorável à recuperação ou à manutenção da qualidade do solo (Silva et al. 2000, Menezes 2002).

O cultivo em solo sem revolvimento, aliado à adição de $\mathrm{C}$ orgânico, por meio do cultivo com adubos verdes, e à manutenção dos resíduos em superfície favorecem a decomposição lenta e gradual destes resíduos, que contêm macro e micronutrientes, em formas orgânicas lábeis, que podem se tornar

1. Trabalho recebido em mar./2009 e aceito para publicação em ago./2010 ( ${ }^{\circ}$ registro: PAT 5841/ DOI: 10.5216/pat.v40i3.5841).

2. Embrapa Arroz e Feijão, Setor de Solos, Santo Antônio de Goiás, GO, Brasil.

E-mails: pmarques@cnpaf.embrapa.br, stone@cnpaf.embrapa.br.

3. Universidade Federal de Goiás, Escola de Agronomia e Engenharia de Alimentos, Setor de Solos, Goiânia, GO, Brasil.

E-mails: pcdacunha@hotmail.com,gleniogm@gmail.com. 
disponíveis para a cultura subsequente, mediante a sua mineralização (Calegari 2004).

Segundo Anghinoni \& Nicolodi (2004), os efeitos proporcionados pelos compostos orgânicos dos resíduos vegetais de plantas de cobertura sobre a química do solo são transientes. No entanto, podem mitigar os efeitos acidificantes causados por grupos carboxílicos e fenólicos, gerados durante a decomposição de resíduos vegetais, pela reação dos adubos nitrogenados amídicos e amoniacais (processo de nitrificação) e pela exportação de minerais como Ca, $\mathrm{Mg}$ e K, pelas colheitas.

Os ânions orgânicos são mais abundantes nas plantas na época de pleno crescimento vegetativo, ou início do florescimento, reduzindo-se com a idade fisiológica da planta, graças à redução nos teores de cátions e $\mathrm{C}$ solúvel. Isto explica a menor capacidade dos resíduos vegetais de culturas comerciais em neutralizar a acidez do solo, correspondendo, em média, a um terço, em relação à capacidade dos resíduos de plantas de cobertura (Franchini et al. 2001).

De acordo com revisão realizada por Pavinato \& Rosolem (2008), tem ocorrido acúmulo de nutrientes nas camadas superficiais do solo, no sistema plantio direto. Os ácidos orgânicos provenientes de plantas podem interagir com a fase sólida e ocupar os sítios de absorção de nutrientes, competindo diretamente com eles e aumentando sua disponibilidade no solo. A adição de resíduos vegetais pode promover, antes da humificação, a elevação do $\mathrm{pH}$, por promover a complexação de $\mathrm{H}$ e Al com compostos do resíduo vegetal, deixando $\mathrm{Ca}, \mathrm{Mg}$ e $\mathrm{K}$ mais livres em solução, o que pode ocasionar aumento na saturação da CTC, por estes cátions de reação básica. Estes compostos também aumentam a mobilidade no perfil do solo dos produtos originados da dissolução do calcário aplicado em superfície. Também, é normal se observar o aumento na disponibilidade de $\mathrm{P}$ no solo, com a adição de resíduos vegetais, tanto pelo $\mathrm{P}$ presente no resíduo como por competição de compostos orgânicos dos resíduos pelos sítios de troca no solo.

A eficácia do sistema plantio direto está relacionada, dentre outros fatores, com a quantidade e a qualidade de resíduos produzidos pelas plantas de cobertura, persistência destes resíduos sobre o solo, velocidade de decomposição e liberação de nutrientes, segundo Torres \& Pereira (2008). Estes autores, comparando seis plantas de cobertura, verificaram que o milheto, o sorgo e a crotalária foram as que apresentaram maiores produções de massa de matéria seca. $\mathrm{O}$ maior acúmulo de $\mathrm{K}$ ocorreu em gramíneas e a maior liberação deste elemento ocorreu no milheto, aveia, braquiária e crotalária, nos primeiros 42 dias após o manejo. Menezes \& Leandro (2004), por sua vez, ao compararem oito culturas de cobertura, observaram que as maiores produções de massa de matéria seca foram obtidas com braquiária e crotalária, sendo notada maior extração de $\mathrm{N}, \mathrm{K}$, $\mathrm{Ca}$ e micronutrientes, pelo trigo sarraceno, e de P, por milheto e braquiária.

Segundo Floss (2000), as palhadas de gramíneas são fornecedoras de nutrientes às culturas sucessoras, a médio e longo prazo, especialmente na camada superficial. Como exemplo, pode-se citar o significativo aumento dos teores de fósforo e potássio nas camadas superficiais do solo sob sistema plantio direto. As leguminosas desempenham um papel fundamental como fornecedoras de nutrientes, quando o sistema plantio direto está estabilizado. O uso de leguminosas tem a vantagem de colocar nutrientes prontamente disponíveis para as culturas sucessoras, devido à rápida decomposição dos resíduos.

É fundamental a utilização de espécies produtoras de palhada, que mobilizem os nutrientes na camada agricultável, retendo-os na sua fitomassa e devolvendo-os ao solo, durante a decomposição (Denardin \& Kochhann 1993). No entanto, há necessidade de se verificar a real contribuição dessas espécies, com a finalidade de se manter ou elevar a fertilidade do solo em áreas sob plantio direto e melhorar a produtividade das culturas comerciais.

Assim, o presente trabalho teve como objetivo avaliar, após quatro anos, as alterações nos atributos químicos do solo cultivado com diferentes culturas de cobertura e, adicionalmente, verificar se elas afetam os valores de $\mathrm{pH}$ e os teores de cálcio e magnésio, um ano após a aplicação de calcário na superfície do solo.

\section{MATERIAL E MÉTODOS}

O experimento foi conduzido na Fazenda Capivara, pertencente à Embrapa Arroz e Feijão, localizada no município de Santo Antônio de Goiás (GO), em Latossolo Vermelho distrófico, com $440 \mathrm{~g} \mathrm{ha}^{-1}$ de areia, $140 \mathrm{~g} \mathrm{ha}^{-1}$ de silte e $420 \mathrm{~g} \mathrm{ha}^{-1} \mathrm{de}$ argila. Na Tabela 1, é possível verificar os resultados da análise química do solo da área experimental, antes da implantação dos tratamentos. 
Tabela 1. Resultados da análise química do solo da área estudada, antes da instalação dos experimentos (Santo Antônio de Goiás, GO, 2001).

\begin{tabular}{ccccccccccc}
\hline \multirow{2}{*}{$\begin{array}{c}\text { Profundidade } \\
\text { do solo }(\mathrm{cm})\end{array}$} & $\begin{array}{c}\mathrm{pH} \text { em } \\
\text { água }\end{array}$ & $\mathrm{Ca}$ & $\mathrm{Mg}$ & $\mathrm{P}$ & $\mathrm{K}$ & $\mathrm{M} .{ }^{*}$ & $\mathrm{Cu}$ & $\mathrm{Zn}$ & $\mathrm{Fe}$ & $\mathrm{Mn}$ \\
\cline { 2 - 11 } & $(1: 2,5)$ & \multicolumn{2}{c}{$\mathrm{cmol}_{\mathrm{c}} \mathrm{dm}^{-3}$} & & $-\mathrm{mg} \mathrm{dm}^{-3}-$ & $\mathrm{g} \mathrm{dm}^{-3}$ & & & $\mathrm{mg} \mathrm{dm}^{-3}$ & \\
\hline $0-5$ & 6,15 & 2,47 & 1,00 & 18,22 & 104,3 & 20,0 & 1,62 & 8,65 & 43,5 & 12,2 \\
$5-10$ & 6,10 & 2,17 & 0,80 & 20,17 & 90,1 & 17,6 & 1,82 & 8,46 & 42,4 & 10,9 \\
$10-20$ & 5,98 & 1,77 & 0,61 & 20,88 & 77,5 & 15,4 & 2,10 & 8,02 & 41,4 & 9,6 \\
\hline
\end{tabular}

* M.O.: matéria orgânica.

Utilizou-se o delineamento experimental de blocos ao acaso, com oito tratamentos e quatro repetições. Os tratamentos consistiram das seguintes culturas de cobertura: braquiária (Brachiaria brizantha cv. Marandú); milho (Zea mays L.) - híbrido HT BRS 3150 - consorciado com braquiária; guandu anão (Cajanus cajan L. Millsp); milheto (Pennisetum glaucum L. R. Br.) - cv. BN-2; capim mombaça (Panicum maximum cv. Mombaça); sorgo granífero (Sorghum bicolor L. Moench) - cv. BR 304; estilosantes (Stylosanthes guianensis cv. Mineirão); e crotalária (Crotalaria juncea L.).

O estudo iniciou-se em novembro de 2001, com o plantio direto das coberturas, que foram adubadas com $400 \mathrm{~kg} \mathrm{ha}^{-1}$ da fórmula 5-30-15 $\left(\mathrm{N}-\mathrm{P}_{2} \mathrm{O}_{5}-\mathrm{K}_{2} \mathrm{O}\right)$. Este procedimento foi repetido anualmente, até novembro de 2006. As parcelas tinham $10 \mathrm{~m}$ de largura por $20 \mathrm{~m}$ de comprimento. Os consumos de sementes no plantio foram de braquiária, mombaça e milho (20 kg ha-1); guandu (25 kg ha-1); milheto e crotalária $\left(40 \mathrm{~kg} \mathrm{ha}^{-1}\right)$; sorgo $\left(10 \mathrm{~kg} \mathrm{ha}^{-1}\right)$; e estilosantes $\left(1,4 \mathrm{~kg} \mathrm{ha}^{-1}\right)$. O estilosantes, devido ao seu pequeno crescimento, e o milho consorciado com braquiária receberam adubação nitrogenada em cobertura de $30 \mathrm{~kg} \mathrm{ha}^{-1}$, utilizando-se o sulfato de amônio.

Todas as culturas de cobertura foram cortadas no mesmo dia, no mês de abril de cada ano, utilizando-se um triturador de palhada e deixando-se este material na superfície do solo. Antes do corte, foram colhidos apenas os grãos de milho e sorgo. Os rendimentos médios anuais de massa de matéria seca da parte aérea das coberturas foram 11,0 t (braquiária); 4,3 t (consorciação do milho com braquiária); 3,6 $\mathrm{t}$ (guandu); 6,6 $\mathrm{t}$ (milheto); 8,2 $\mathrm{t}$ (mombaça); 4,6 $\mathrm{t}$ (sorgo); 2,6 t (estilosantes); e 6,9 t (crotalária).

Sessenta dias após o corte das culturas, em todos os anos, foi realizada semeadura do feijão, conduzida de junho a setembro, sob irrigação por aspersão. Antes da semeadura, aplicou-se, em toda a área, o herbicida glifosate, na dose de $2,4 \mathrm{~kg}$ i.a. ha- ${ }^{-1}$. A adubação de base do feijoeiro foi de $400 \mathrm{~kg} \mathrm{ha}^{-1}$, utilizando-se a fórmula 4-25-15+ $\mathrm{Zn}\left(\mathrm{N}-\mathrm{P}_{2} \mathrm{O}_{5}-\mathrm{K}_{2} \mathrm{O}\right)$. Utilizou-se ureia como fonte de $\mathrm{N}$, na quantidade de $60 \mathrm{~kg}$ de $\mathrm{N} \mathrm{ha}^{-1}$, em uma única adubação de cobertura, no início do florescimento do feijoeiro.

Foram realizadas três amostragens de solo para análise química, sendo a primeira antes da instalação dos experimentos (controle), em novembro de 2001, caracterizando a área em estudo, e as demais em novembro de 2005 e 2006, nas profundidades de $0-5 \mathrm{~cm}$, $5-10 \mathrm{~cm}$ e $10-20 \mathrm{~cm}$. De cada parcela, foram coletadas amostras compostas, oriundas de cinco subamostras de cada tratamento, e, após homogeneização, as amostras foram acondicionadas em sacos plásticos, identificadas e levadas ao laboratório para análise. Logo após a coleta de 2005, aplicou-se, em toda a área experimental, em superfície, sem revolvimento, $4.000 \mathrm{~kg} \mathrm{ha}^{-1}$ de calcário dolomítico. Foram realizadas as seguintes determinações: $\mathrm{pH}, \mathrm{Ca}, \mathrm{Mg}, \mathrm{P}, \mathrm{K}$, $\mathrm{Cu}, \mathrm{Zn}, \mathrm{Fe}, \mathrm{Mn}$ e matéria orgânica do solo.

$\mathrm{O} \mathrm{pH}$ foi determinado em água. $\mathrm{O} \mathrm{Ca}$ e o $\mathrm{Mg}$ foram extraídos em $\mathrm{KCl}$ a $1 \mathrm{~N}$ e o fósforo e potássio em solução de Mehlich $1\left(\mathrm{HCl}\right.$ a $0,5 \mathrm{~N}+\mathrm{H}_{2} \mathrm{SO}_{4}$ a $0,025 \mathrm{~N})$. Os micronutrientes foram determinados por espectrofotômetro de absorção atômica, utilizando-se o extrator Mehlich 1. A matéria orgânica foi determinada pelo método de Walkley e Black. As análises laboratoriais foram realizadas de acordo com procedimentos da Embrapa (1997).

Os dados relativos à amostragem realizada em 2005 foram analisados efetuando-se a análise de variância por profundidade, utilizando-se o procedimento GLM do programa estatístico SAS (Sas Institute 1999), sendo as médias comparadas pelo teste Tukey, a 5\% de probabilidade. As médias dos tratamentos foram comparadas com os valores iniciais dos atributos químicos, considerados como controle, pelo teste de Dunnett, a 5\%. Adicional- 
mente, foi feita a análise do efeito da profundidade de amostragem. Foi realizada, também, a análise de variância por profundidade dos dados relativos ao pH e teores de cálcio e magnésio obtidos em 2006. Para estes atributos, também foi analisado o efeito dos anos de amostragem (2005 e 2006).

\section{RESULTADOS E DISCUSSÃO}

As culturas de cobertura diferiram, significativamente, quanto ao seu efeito no $\mathrm{pH}$ do solo, na camada de 0-5 $\mathrm{cm}$ de profundidade (Tabela 2). $\mathrm{O}$ valor do $\mathrm{pH}$ no solo do tratamento em que o estilosantes foi usado como cultura de cobertura foi menor que no solo dos tratamentos com crotalária, sorgo, braquiária e milheto. Nesta camada, além do estilosantes, as coberturas de milho consorciado com braquiária e guandu propiciaram valores de $\mathrm{pH}$ do solo significativamente menores do que os valores iniciais. As duas primeiras coberturas também apresentaram este desempenho, na camada de $5-10 \mathrm{~cm}$. A adubação nitrogenada feita com o sulfato de amônio no estilosantes e no milho consorciado com braquiária deve ter contribuído para a redução no $\mathrm{pH}$. Adubos amídicos e amoniacais têm a propriedade acidificante do solo, pois, no processo de nitrificação, há liberação de íons $\mathrm{H}^{+}$(Taiz \& Zaiger 2004). Ademais, a extração de bases pela colheita do milho também deve ter contribuído para essa redução no $\mathrm{pH}$, como também observaram Almeida et al. (2008). No caso do guandu, tal processo pode ser devido a exudações de ácidos pelas raízes que atuam diretamente no $\mathrm{pH}$

Tabela 2. Valores de pH e teores de Ca, Mg, P, K e matéria orgânica (M.O.), em função de culturas de cobertura e profundidades de amostragem do solo (Santo Antônio de Goiás, GO, 2005).

\begin{tabular}{|c|c|c|c|c|c|c|}
\hline Cultura & $\mathrm{pH}$ & $\mathrm{Ca}$ & $\mathrm{Mg}$ & $\mathrm{P}$ & $\mathrm{K}$ & M.O. \\
\hline de cobertura & água $(1: 2,5)$ & $\mathrm{cmol} \mathrm{dm}^{-3}$ & $\mathrm{cmol}_{\mathrm{c}} \mathrm{dm}^{-3}$ & $\mathrm{mg} \mathrm{dm}^{-3}$ & $\mathrm{mg} \mathrm{dm}^{-3}$ & $\mathrm{~g} \mathrm{dm}^{-3}$ \\
\hline \multicolumn{7}{|c|}{ Profundidade do solo: $0-5 \mathrm{~cm}$} \\
\hline Braquiária & $6,02 \mathrm{a}$ & 2,32 & $1,13 \mathrm{ab}$ & 35,78 & 101,5 & 19,5 \\
\hline Milho e braquiária & $5,78 \mathrm{ab} *$ & 2,07 & $0,67 \mathrm{~b}$ & 27,48 & 84,8 & 19,8 \\
\hline Guandu & $5,72 \mathrm{ab}^{*}$ & 2,38 & $0,70 \mathrm{~b}$ & 42,68 & 70,5 & 19,8 \\
\hline Milheto & $6,10 \mathrm{a}$ & 2,68 & $1,13 \mathrm{ab}$ & 25,83 & 110,8 & 19,5 \\
\hline Mombaça & $5,98 \mathrm{ab}$ & 2,52 & $1,34 \mathrm{a}$ & 25,95 & 67,5 & 19,8 \\
\hline Sorgo & $6,02 \mathrm{a}$ & 2,38 & $0,82 \mathrm{ab}$ & 41,65 & 92,5 & 20,0 \\
\hline Estilosantes & $5,5 \bar{b} \mathrm{~b}^{*}$ & 2,09 & $0,58 \mathrm{~b}$ & 27,03 & 72,5 & 19,5 \\
\hline Crotalária & $6,00 \mathrm{a}$ & 2,90 & $1,01 \mathrm{ab}$ & 21,38 & 64,0 & 19,8 \\
\hline $\mathrm{DMS}^{1}$ & 0,44 & 1,05 & 0,57 & 39,40 & 54,2 & 1,7 \\
\hline $\mathrm{CV}^{2}(\%)$ & 3,19 & 18,50 & 26,41 & 54,32 & 27,89 & 3,59 \\
\hline Controle & 6,15 & 2,47 & 1,00 & 18,22 & 104,3 & 20,0 \\
\hline \multicolumn{7}{|c|}{ Profundidade do solo: $5-10 \mathrm{~cm}$} \\
\hline Braquiária & 5,88 & 2,07 & 0,86 & 39,53 & 78,2 & 18,2 \\
\hline Milho e braquiária & $5,52 *$ & 1,69 & 0,48 & 45,78 & 68,8 & 18,2 \\
\hline Guandu & 5,72 & 2,14 & 0,64 & 45,00 & 61,8 & 18,0 \\
\hline Milheto & 5,80 & 1,80 & 0,59 & $58,70 *$ & 97,5 & 18,2 \\
\hline Mombaça & 5,82 & 2,00 & 0,87 & 31,73 & 61,2 & 18,8 \\
\hline Sorgo & 5,75 & 2,00 & 0,52 & 48,08 & 67,2 & 18,8 \\
\hline Estilosantes & $5,55 *$ & 1,73 & 0,44 & 30,65 & 59,5 & 18,2 \\
\hline Crotalária & 5,95 & 2,36 & 0,74 & 29,43 & 68,5 & 18,5 \\
\hline DMS & 0,56 & 1,30 & 0,54 & 44,70 & 50,6 & 2,0 \\
\hline CV $(\%)$ & 4,20 & 28,08 & 35,52 & 46,43 & 30,72 & 4,65 \\
\hline Controle & 6,10 & 2,17 & 0,80 & 20,17 & 90,1 & 17,6 \\
\hline \multicolumn{7}{|c|}{ Profundidade do solo: $10-20 \mathrm{~cm}$} \\
\hline Braquiária & 5,72 & 1,42 & 0,52 & 23,20 & 65,5 & 16,0 \\
\hline Milho e braquiária & 5,50 & 1,48 & 0,41 & $50,52 *$ & 58,2 & 16,0 \\
\hline Guandu & 5,62 & 1,60 & 0,41 & $49,48 *$ & 67,5 & 16,2 \\
\hline Milheto & 5,78 & 1,78 & 0,56 & $51,50 *$ & 80,0 & 16,0 \\
\hline Mombaça & 5,62 & 1,46 & 0,59 & 36,75 & 55,5 & 16,5 \\
\hline Sorgo & 5,70 & 1,78 & 0,45 & $51,38 *$ & 73,8 & 16,5 \\
\hline Estilosantes & 5,50 & 1,44 & 0,37 & 39,78 & 56,0 & 16,0 \\
\hline Crotalária & 5,70 & 1,73 & 0,52 & 33,68 & 59,5 & 15,2 \\
\hline DMS & 0,61 & 1,39 & 0,39 & 32.79 & 43,2 & 2,0 \\
\hline CV $(\%)$ & 4,62 & 37,38 & 34,66 & 33,31 & 28,58 & 5,32 \\
\hline Controle & 5,98 & 1,77 & 0,61 & 20,88 & 77,5 & 15,4 \\
\hline
\end{tabular}

${ }^{1} \mathrm{DMS}$ : diferença mínima significativa; ${ }^{2} \mathrm{CV}$ : coeficiente de variação.

* Médias seguidas da mesma letra, nas colunas, não diferem, significativamente, pelo teste Tukey, a $5 \%$ de probabilidade, e as seguidas de um asterisco diferem, significativamente, do controle, pelo teste de Dunnett, a 5\%. 
do solo. Esta cobertura e o estilosantes foram os que apresentaram menor rendimento médio de massa de matéria seca. De acordo com Paul et al. (2001), o efeito dos resíduos vegetais no aumento do $\mathrm{pH}$ do solo depende da quantidade de resíduos com cinzas de alta alcalinidade.

A acidificação ou alcalinização do solo depende do balanço entre a mineralização e subsequente nitrificação do N orgânico adicionado e sua associação e, particularmente, da oxidação dos ânions orgânicos adicionados. Almeida et al. (2008), após três anos de plantio direto, também não verificaram efeito significativo da crotalária e do milheto sobre o $\mathrm{pH}$ do solo.

O teor de magnésio no solo do tratamento em que a mombaça foi usada como cultura de cobertura foi maior que no solo dos tratamentos com guandu, estilosantes e milho consorciado com braquiária, na camada de 0-5 cm de profundidade (Tabela 2). Como estas duas últimas culturas receberam adubação nitrogenada na forma amoniacal, é possível que a ocorrência de reações que produzem $\mathrm{H}^{+}$(nitrificação) tenha contribuído para o movimento do magnésio para camadas mais profundas do solo, acompanhando o ânion $\mathrm{NO}_{3}$ - No caso do guandu, isto pode ter ocorrido devido à exudação de ácidos pelas raízes, as quais atuam diretamente no $\mathrm{pH}$ do solo. $\mathrm{O}$ maior teor de magnésio no solo sob as demais coberturas pode ser devido ao fato de que a adição de resíduos vegetais pode promover, antes da humificação, a elevação do pH, em razão da complexação de $\mathrm{H}$ e Al com compostos do resíduo vegetal, deixando $\mathrm{Ca}$, Mg e K mais livres em solução, o que pode ocasionar aumento na saturação da CTC por esses cátions de reação básica (Pavinato \& Rosolem 2008).

$\mathrm{O}$ valor do $\mathrm{pH}$ e o teor de magnésio do solo, nas camadas de $5-10 \mathrm{~cm}$ e $10-20 \mathrm{~cm}$, e os demais atributos químicos, nas três camadas avaliadas, não foram afetados, significativamente, pelas culturas de cobertura (Tabelas 2 e 3). Em relação à matéria orgânica, Almeida et al. (2008), após três anos de plantio direto, também não verificaram efeito significativo das culturas de cobertura guandu, crotalária, mucuna, milheto e do pousio sobre o seu teor no solo.

As adubações realizadas nos plantios de verão e outono-inverno contribuíram para o aumento no teor de fósforo do solo. O milheto propiciou teores de fósforo no solo, nas camadas de $5-10 \mathrm{~cm}$ e $10-20 \mathrm{~cm}$, maiores que os iniciais (Tabela 2). Nesta última camada, as coberturas de sorgo, milho consorciado
Tabela 3. Teores de $\mathrm{Cu}, \mathrm{Zn}, \mathrm{Fe}$ e $\mathrm{Mn}$, em função de culturas de cobertura e profundidades de amostragem do solo (Santo Antônio de Goiás, GO, 2005).

\begin{tabular}{|c|c|c|c|c|}
\hline \multirow{2}{*}{$\begin{array}{l}\text { Cultura de } \\
\text { cobertura }\end{array}$} & $\mathrm{Cu}$ & $\mathrm{Zn}$ & $\mathrm{Fe}$ & $\mathrm{Mn}$ \\
\hline & \multicolumn{4}{|c|}{$\mathrm{mg} \mathrm{dm}^{-3}$} \\
\hline \multicolumn{5}{|c|}{ Profundidade do solo: $0-5 \mathrm{~cm}$} \\
\hline Braquiária & 1,58 & 9,45 & 37,8 & 10,8 \\
\hline Milho e braquiária & 2,48 & 10,48 & 35,0 & 11,2 \\
\hline Guandu & 1,62 & 10,48 & 31,2 & 11,5 \\
\hline Milheto & 1,50 & 9,90 & 42,5 & 12,8 \\
\hline Mombaça & 1,38 & 11,05 & 34,2 & 13,2 \\
\hline Sorgo & 1,55 & 9,48 & 32,2 & 12,8 \\
\hline Estilosante & 1,45 & 10,42 & 29,5 & 11,2 \\
\hline Crotalári & 1,40 & 9,32 & 31,2 & 10,5 \\
\hline $\mathrm{DMS}^{1}$ & 1,32 & 4,30 & 21,6 & 6,1 \\
\hline $\mathrm{CV}^{2}(\%)$ & 34,74 & 18,24 & 26,89 & 22,28 \\
\hline Controle & 1,62 & 8,65 & 43,5 & 12,2 \\
\hline \multicolumn{5}{|c|}{ Profundidade do solo: $5-10 \mathrm{~cm}$} \\
\hline Braquiária & 1,62 & 7,88 & 46,0 & 10,2 \\
\hline Milho e braquiária & 2,42 & 10,92 & 35,8 & 10,2 \\
\hline Guandu & 1,68 & 9,58 & 33,2 & 9,8 \\
\hline Milheto & 2,10 & 9,15 & 37,2 & 8,8 \\
\hline Mombaça & 1,55 & 8,42 & 34,2 & 9,8 \\
\hline & 1,82 & 9,50 & 35,2 & 10,2 \\
\hline Estilosante & 1,60 & 9,42 & 30,5 & 8,8 \\
\hline Crotalária & 1,65 & 8,10 & 33,5 & 8,5 \\
\hline DMS & 1,12 & 4,59 & 18,2 & 6,5 \\
\hline CV (\%) & 26,38 & 21,48 & 21,73 & 29,07 \\
\hline Controle & 1,82 & 8,46 & 42,4 & 10,9 \\
\hline \multicolumn{5}{|c|}{ Profundidade do solo: $10-20 \mathrm{~cm}$} \\
\hline Braquiária & 2,00 & 7,55 & 36,0 & 7,0 \\
\hline Milho e braquiária & 2,75 & 10,58 & 34,5 & 8,2 \\
\hline Guandu & 1,83 & 9,08 & 35,2 & 7,8 \\
\hline Milh & 1,68 & 7,95 & 38,0 & 7,0 \\
\hline Mombaça & 1,78 & 7,90 & 32,2 & 7,2 \\
\hline & 2,35 & 9,40 & 37,5 & 9,0 \\
\hline & 1,75 & 8,40 & 29,5 & 6,5 \\
\hline Crotalária & 1,83 & 8,88 & 30,5 & 6,5 \\
\hline DMS & 1,26 & 4,50 & 13,6 & 7,5 \\
\hline CV $(\%)$ & 26,97 & 22,07 & 17,03 & 43,42 \\
\hline Controle & 2,10 & 8,02 & 41,4 & 9,6 \\
\hline
\end{tabular}

${ }^{1}$ DMS: diferença mínima significativa; ${ }^{2} \mathrm{CV}$ : coeficiente de variação.

com braquiária e guandu também propiciaram maiores teores de fósforo no solo, em comparação com os observados no início do experimento. Algumas culturas potencializam o aumento da quantidade de micro-organismos solubilizadores de fosfato, como é o caso do guandu (Carneiro et al. 2004). Menezes \& Leandro (2004), comparando oito culturas de cobertura, verificaram que o milheto e a braquiária acumularam as maiores quantidades de fósforo.

Os valores de $\mathrm{pH}, \mathrm{Ca}$ e $\mathrm{Mg}$ encontrados no trabalho são considerados adequados e os de $\mathrm{P}, \mathrm{K}$ e micronutrientes, de acordo com Souza \& Lobato (2004), são considerados elevados. Entretanto, na maioria dos tratamentos, o teor de potássio no solo apresentou tendência a diminuir, em relação aos 
valores iniciais, o que evidencia que as adubações realizadas podem não ter sido suficientes para manter o teor deste nutriente no solo. Outra possibilidade é que tenha havido lixiviação de $\mathrm{K}$ para camadas mais profundas do solo, uma vez que a CTC efetiva e a força de adsorção de $\mathrm{K}$ dos solos de Cerrado são, normalmente, baixas e que o experimento tenha sido conduzido sob irrigação. Contudo, a maior presença de resíduos culturais na superfície do solo sob algumas coberturas deve ter contribuído para minimizar este problema, pelo acúmulo de $\mathrm{K}$ na camada de $0-5 \mathrm{~cm}$ de profundidade. Entre os micronutrientes, o alto teor de zinco no solo se deve à fórmula utilizada na cultura do feijoeiro, contendo este elemento.

Houve tendência de as gramíneas propiciarem maiores valores dos atributos químicos do solo, destacando-se o milheto, quanto aos teores de potássio, fósforo (nas camadas mais profundas) e ferro; o capim mombaça, quanto aos teores de magnésio; e o milho consorciado com braquiária, quanto aos teores de cobre e zinco. Entre as leguminosas, a crotalária destacou-se, quanto aos teores de cálcio.

Torres \& Pereira (2008) verificaram maior acúmulo de $\mathrm{K}$ em gramíneas e maior liberação deste elemento no milheto, aveia, braquiária e crotalária, nos primeiros 42 dias após o manejo. Menezes \& Leandro (2004) observaram maior extração de P pelo milheto e braquiária. Silva et al. (2003) encontraram valores de $222 \mathrm{~kg} \mathrm{ha}^{-1}$, para $\mathrm{N}$, e $275 \mathrm{~kg} \mathrm{ha}^{-1}$, para $\mathrm{K}$, como as quantidades destes nutrientes restituídas ao solo pelo milheto, aos 55 dias de idade. Braz et al. (2004) observaram que estas quantidades vão depender do teor do nutriente no limbo foliar e da produtividade de matéria seca e relataram valores de $349 \mathrm{~kg} \mathrm{ha}^{-1}, 36 \mathrm{~kg} \mathrm{ha}^{-1}$ e $314 \mathrm{~kg} \mathrm{ha}^{-1}$, respectivamente, para $\mathrm{N}, \mathrm{Pe} \mathrm{K}$, como as quantidades destes nutrientes acumuladas pela cultura.

O comportamento menos expressivo da braquiária consorciada com milho e do sorgo pode ser explicado pela menor biomassa da braquiária, quando em consórcio, e pela colheita dos grãos produzidos pelo milho e pelo sorgo, caracterizando exportação de nutrientes da área. Estes resultados reforçam as observações de De Maria \& Castro (1993), os quais relataram que diferentes sucessões e rotações podem alterar o teor de nutrientes no solo, em vista das diferenças em exigência nutricional, profundidade de raízes e quantidade de material vegetal que retorna ao solo.

De maneira geral, os atributos químicos do solo apresentaram maiores valores na camada de $0-5 \mathrm{~cm}, \mathrm{o}$ que está de acordo com Pavinato \& Rosolem (2008). As exceções são o fósforo e o cobre, para os quais os maiores valores encontram-se nas camadas de 5-10 cm e 10-20 cm (Tabela 4). Isto pode ser explicado pelo fato de as adubações das culturas de cobertura e do feijoeiro, nos diferentes anos de plantio, serem feitas em maiores profundidades, sempre abaixo da profundidade de colocação das sementes, e também pelo fato de ser o fósforo um elemento pouco móvel no solo. De Maria \& Castro (1993) também encontraram aumento no teor de P disponível no solo, na camada de 5-10 $\mathrm{cm}$ de profundidade.

Na Tabela 5, são apresentados os valores de $\mathrm{pH}$ e os teores de cálcio e magnésio, um ano após a aplicação de calcário na superfície do solo. Observase que as culturas de cobertura não diferiram, significativamente, quanto a estes atributos químicos. Entretanto, em relação aos valores obtidos antes da aplicação do calcário, no ano de 2005 (Tabela 2), verifica-se que, em 2006, os teores de cálcio e magnésio aumentaram tanto na camada de $0-5 \mathrm{~cm}$ como na de 5-10 cm (Tabela 6), o que demonstra que houve movimentação desses cátions no perfil do solo. Caires et al. (2000) e Tissi et al. (2004) também observaram correção da acidez do solo em profundidade, em latossolos de textura média e muito argilosa.

Tabela 4. Valores dos atributos químicos do solo, em função da profundidade (Santo Antônio de Goiás, GO, 2005).

\begin{tabular}{|c|c|c|c|c|c|c|c|c|c|c|}
\hline \multirow{2}{*}{$\begin{array}{l}\text { Profundidade } \\
\text { do solo }(\mathrm{cm})\end{array}$} & $\mathrm{pH}$ & $\mathrm{Ca}$ & $\mathrm{Mg}$ & $\mathrm{P}$ & $\mathrm{K}$ & $\mathrm{Cu}$ & $\mathrm{Zn}$ & $\mathrm{Fe}$ & $\mathrm{Mn}$ & M.O. ${ }^{1}$ \\
\hline & água $(1: 2,5)$ & \multicolumn{2}{|c|}{$\mathrm{cmol}_{\mathrm{c}} \mathrm{dm}^{-3}$} & \multicolumn{6}{|c|}{$\mathrm{mg} \mathrm{dm}^{-3}$} & $\mathrm{~g} \mathrm{dm}^{-3}$ \\
\hline $0-5$ & $5,89 \mathrm{a}^{2}$ & $2,42 \mathrm{a}$ & $0,93 \mathrm{a}$ & $31,0 \mathrm{~b}$ & $83 \mathrm{a}$ & $1,62 \mathrm{~b}$ & $10,1 \mathrm{a}$ & $34 \mathrm{a}$ & $11,8 \mathrm{a}$ & $19,7 \mathrm{a}$ \\
\hline $5-10$ & $5,75 \mathrm{~b}$ & $1,97 \mathrm{~b}$ & $0,65 \mathrm{~b}$ & $41,1 \mathrm{a}$ & $70 \mathrm{ab}$ & $1,81 \mathrm{ab}$ & $9,1 \mathrm{ab}$ & $36 a$ & $9,5 \mathrm{~b}$ & $18,4 \mathrm{~b}$ \\
\hline $10-20$ & $5,64 \mathrm{~b}$ & $1,59 \mathrm{c}$ & $0,48 \mathrm{c}$ & $42,0 \mathrm{a}$ & $65 \mathrm{~b}$ & $1,99 \mathrm{a}$ & $8,7 \mathrm{~b}$ & $34 \mathrm{a}$ & $7,4 \mathrm{c}$ & $16,1 \mathrm{c}$ \\
\hline
\end{tabular}

M.O.: matéria orgânica.

${ }^{2}$ Médias seguidas pela mesma letra, na coluna, não apresentam diferenças significativas, a $5 \%$ de probabilidade, pelo teste Tukey. 
Tabela 5. Valores de pH e teores de Ca e Mg, em função de culturas de cobertura e profundidades de amostragem do solo (Santo Antônio de Goiás, GO, 2006).

\begin{tabular}{|c|c|c|c|c|c|c|c|c|c|}
\hline \multirow{4}{*}{$\begin{array}{c}\text { Cultura } \\
\text { de cobertura }\end{array}$} & \multicolumn{9}{|c|}{ Profundidade do solo $(\mathrm{cm})$} \\
\hline & $0-5$ & $5-10$ & $10-20$ & $0-5$ & $5-10$ & $10-20$ & $0-5$ & $5-10$ & $10-20$ \\
\hline & \multicolumn{3}{|c|}{$\mathrm{pH}$} & \multicolumn{3}{|c|}{$\mathrm{Ca}$} & \multicolumn{3}{|c|}{$\mathrm{Mg}$} \\
\hline & \multicolumn{3}{|c|}{ _ água $(1: 2,5)$} & \multicolumn{6}{|c|}{$\mathrm{cmol}_{\mathrm{c}} \mathrm{dm}^{-3}$} \\
\hline Braquiária & 6,52 & 5,85 & 5,32 & 4,05 & 2,52 & 1,53 & 1,76 & 1,00 & 0,51 \\
\hline Milho e braquiária & 6,52 & 5,75 & 5,28 & 3,69 & 2,25 & 1,55 & 1,54 & 0,81 & 0,50 \\
\hline Guandu & 6,70 & 5,95 & 5,38 & 4,34 & 2,42 & 1,44 & 1,59 & 0,88 & 0,45 \\
\hline Milheto & 6,60 & 6,00 & 5,40 & 3.92 & 2.59 & 1.55 & 1.65 & 0,92 & 0,53 \\
\hline Mombaça & 6,45 & 5,78 & 5,28 & 3,89 & 2,25 & 1,24 & 1,90 & 1,12 & 0,62 \\
\hline Sorgo & 6,72 & 6,32 & 5,48 & 4,25 & 3,08 & 1,66 & 1,68 & 1,20 & 0,52 \\
\hline Estilosantes & 6,40 & 6,00 & 5,20 & 3,87 & 2,95 & 1,55 & 1,40 & 1,04 & 0,53 \\
\hline Crotalária & 6,35 & 5,95 & 5,62 & 3,78 & 2,56 & 1,94 & 1,57 & 0,91 & 0,64 \\
\hline $\mathrm{DMS}^{1}$ & 0,57 & 1,17 & 1,14 & 1.67 & 1.98 & 1.58 & 0,52 & 0,99 & 0,66 \\
\hline $\mathrm{CV}^{2}(\%)$ & 3,72 & 8,43 & 9,04 & 17,93 & 32,84 & 43,21 & 13,58 & 43,03 & 52,22 \\
\hline
\end{tabular}

${ }^{1}$ DMS: diferença mínima significativa; ${ }^{2} \mathrm{CV}$ : coeficiente de variação.

Tabela 6. Teores de $\mathrm{Ca}$ e $\mathrm{Mg}$, em função de anos de avaliação e profundidades de amostragem do solo (Santo Antônio de Goiás, $\mathrm{GO})$.

\begin{tabular}{|c|c|c|c|c|c|c|}
\hline \multirow{4}{*}{ Ano } & \multicolumn{6}{|c|}{ Profundidade do solo $(\mathrm{cm})$} \\
\hline & $0-5$ & $5-10$ & $10-20$ & $0-5$ & $5-10$ & $10-20$ \\
\hline & & $\mathrm{Ca}$ & & & $\mathrm{Mg}$ & \\
\hline & & & - & & & \\
\hline 2005 & 2,42 & 1,97 & 1,59 & 0,93 & 0,65 & 0,48 \\
\hline 2006 & 3,98 & 2,58 & 1,56 & 1,64 & 0,99 & 0,54 \\
\hline Significância ${ }^{1}$ & ** & $* *$ & ns & $* *$ & $* *$ & ns \\
\hline
\end{tabular}

Contraste ano $\mathrm{x}$ profundidade: $* *$ significativo $(\mathrm{p}<0,01) ; \mathrm{ns}=$ não significativo.

Segundo Franchini et al. (1999), um dos principais mecanismos responsáveis pela eficiência da correção da acidez do solo, com a aplicação superficial de calcário em plantio direto, é a liberação de compostos hidrossolúveis de baixa massa molar pelos materiais vegetais presentes na superfície do solo. A presença de certos materiais vegetais é capaz de potencializar o efeito da calagem, mobilizando a chamada frente alcalina. Esses compostos orgânicos apresentam capacidade de complexar cálcio e magnésio, elevar o $\mathrm{pH}$ e neutralizar o alumínio em profundidade (Araújo 2003).

De acordo com Moraes (2005), se houver acidez, o calcário aplicado na superfície do solo reage com os íons presentes na solução do solo, liberando $\mathrm{Ca}^{2+} \mathrm{e} \mathrm{Mg}^{2+}$ trocáveis, que se movimentam no solo, se houver ânions livres, ou, caso contrário, o calcário permanece na superfície. Assim, a aplicação superficial de calcário tem sido o gargalo do sistema plantio direto, em várias partes do mundo. Ainda, segundo o autor, existem muitas pesquisas sobre o assunto, onde os resultados, entretanto, são, muitas vezes, contraditórios, já que, às vezes, a aplicação é eficiente na correção da acidez, tanto de superfície como de subsuperfície, ao passo que, em outras ocasiões, os efeitos são limitados aos primeiros $5 \mathrm{~cm}$ de profundidade.

\section{CONCLUSÕES}

1. As culturas de cobertura afetaram o pH e o teor de magnésio do solo, na camada superficial.

2. O solo sob milheto apresentou maiores teores de fósforo, nas camadas subsuperficiais, em relação aos teores iniciais.

3. Houve tendência de o solo sob cultivo de gramíneas apresentar maiores valores de atributos químicos que quando sob cultivo de leguminosas.

4. Os teores de fósforo e cobre foram maiores nas camadas subsuperficiais do solo, enquanto os demais atributos químicos apresentaram maiores valores na camada superficial.

5. Houve movimentação de $\mathrm{Ca}$ e $\mathrm{Mg}$ no perfil do solo, após um ano da aplicação do calcário na superfície. 


\section{REFERÊNCIAS}

ALMEIDA, V. P. de et al. Rotação de culturas e propriedades físicas e químicas em Latossolo Vermelho de Cerrado sob preparo convencional e semeadura direta em adoção. Revista Brasileira de Ciência do Solo, Viçosa, v. 32, n. 3, p. 1227-1237, 2008.

ANGHINONI, I.; NICOLODI, M. Estratégias de calagem no sistema plantio direto. In: REUNIÃO BRASILEIRA DE FERTILIDADE DO SOLO E NUTRIÇÃO DE PLANTAS - FERTBIO 2004, 26., 2004, Lages. Anais... Lages: Sociedade Brasileira de Ciência do Solo, 2004. 1 CD-ROM.

ARAÚJO, A. R. Calagem e extratos vegetais hidrossolúveis na movimentação de ions em solo. 2003. 85 f. Dissertação (Mestrado em Ciência do Solo)-Departamento de Ciência do Solo, Universidade Federal de Lavras, Lavras, 2003.

BRAZ, A. J. B. P. et al. Acumulação de nutrientes em folhas de milheto e dos capins braquiária e mombaça. Pesquisa Agropecuária Tropical, Goiânia, v. 34, n. 2, p. 83-87, 2004.

CAIRES, E. F.; BANZATO, D. A.; FONSECA, A. F. Calagem na superfície em sistema plantio direto. Revista Brasileira de Ciência do Solo, Viçosa, v. 24, n. 1, p. 161169, 2000.

CALEGARI, A. Alternativa de rotação de culturas para plantio direto. Revista Plantio Direto, Passo Fundo, v. 80, n. 2, p. 62-70, 2004.

CARNEIRO, R. G. et al. Indicadores biológicos associados ao ciclo do fósforo em solos de Cerrado sob plantio direto e plantio convencional. Pesquisa Agropecuária Brasileira, Brasília, DF, v. 39, n. 7, p. 661-669, 2004.

DE MARIA, I. C.; CASTRO, O. M. de. Fósforo, potássio e matéria orgânica em um Latossolo Roxo, sob sistemas de manejo com milho e soja. Revista Brasileira de Ciência do Solo, Campinas, v. 17, n. 3, p. 471-477, 1993.

DENARDIN, J. E.; KOCHHANN, R. A. Requisitos para a implantação e a manutenção do sistema plantio direto. In: PLANTIO direto no Brasil. Passo Fundo: Aldeia Norte, 1993. p. 19-27.

EMPRESA BRASILEIRA DE PESQUISA AGROPECUÁRIA (Embrapa). Manual de métodos de análise de solo. 2. ed. Rio de Janeiro: Embrapa Solos, 1997. (Documentos, 1).

FLOSS, E. Benefícios da biomassa de aveia ao sistema de semeadura direta. Revista Plantio Direto, Passo Fundo, v. 57, n. 1, p. 25-29, 2000.

FRANCHINI, J. C. et al. Alterações químicas em solos ácidos após a aplicação de resíduos vegetais. Revista Brasileira de Ciência do Solo, Viçosa, v. 23, n. 3, p. 533542, 1999.
FRANCHINI, J. C. et al. Rapid transformations of plant water-soluble organic compounds in relation to cation mobilization in an acid Oxisol. Plant and Soil, The Hague, v. 231, n. 1, p. 55-63, 2001.

MENEZES, L. A. S. Alteração de propriedades químicas e físicas do solo em função da fitomassa de plantas de cobertura. 2002. 73 f. Dissertação (Mestrado em Agronomia)-Escola de Agronomia e Engenharia de Alimentos, Universidade Federal de Goiás, Goiânia, 2002.

MENEZES, L. A. S.; LEANDRO, W. M. Avaliação de espécies de coberturas do solo com potencial de uso em sistema de plantio direto. Pesquisa Agropecuária Tropical, Goiânia, v. 34, n. 3, p. 173-180, 2004.

MORAES, M. F. de. Mobilidade de ions em solo ácido com aplicação de calcário e material vegetal em superfície. 2005. 80 f. Dissertação (Mestrado em Agricultura Tropical e Subtropical)-Instituto Agronômico, Campinas, 2005.

PAUL, K. I.; BLACK, A. S.; CONYERS, M. K. Effect of plant residue return on the development of surface soil $\mathrm{pH}$ gradients. Biology and Fertility of Soils, Berlin, v. 33, n. 1, p. 75-82, 2001.

PAVINATO, P. S.; ROSOLEM, C. A. Disponibilidade de nutrientes no solo: decomposição e liberação de compostos orgânicos de resíduos vegetais. Revista Brasileira de Ciência do Solo, Viçosa, v. 32, n. 3, p. 911-920, 2008.

SAS INSTITUTE INC. SAS/STAT procedure guide for personal computers: version 5. Cary: SAS Institute, 1999.

SILVA, F. L. et al. Potencial de restituição de nutrientes através de plantas de cobertura em plantio direto no Tocantins. In: CONGRESSO BRASILEIRO DE CIÊNCIA DO SOLO, 29., 2003, Ribeirão Preto. Anais... Ribeirão Preto: Unesp, 2003. 1 CD-ROM.

SILVA, V. R.; REINERT, D. J.; REICHERT, J. M. Densidade do solo, atributos químicos e sistema radicular do milho sob plantio direto afetados pelo pastejo e manejo do solo. Revista Brasileira de Ciência do Solo, Viçosa, v. 24, n. 1, p. 191-199, 2000.

SOUZA, D. M. G. de; LOBATO, E. Cerrado: correção do solo e adubação. 2. ed. Brasília, DF: Embrapa Informação Tecnológica, 2004.

TAIZ, L.; ZEIGER, E. Fisiologia vegetal. 3. ed. Porto Alegre: Artmed, 2004.

TISSI, J. A.; CAIRES, E. F.; PAULETTI, V. Efeitos da calagem em semeadura direta de milho. Bragantia, Campinas, v. 63, n. 3, p. 405-413, 2004.

TORRES, J. L. R.; PEREIRA, M. G. Dinâmica do potássio nos resíduos vegetais de plantas de cobertura no Cerrado. Revista Brasileira de Ciência do Solo, Viçosa, v. 32, n. 4, p. 1609-1618, 2008. 